\title{
On the performance of piezoelectric harvesters loaded by finite width impulses
}

\author{
A. Doria ${ }^{\text {a,* }}$, C. Medè ${ }^{\text {a }}$, D. Desideri ${ }^{\text {a }}$, A. Maschio ${ }^{\text {a }}$, L. Codecasa ${ }^{\text {b }}$, F. Moro ${ }^{\text {a }}$ \\ a Dipartimento di Ingegneria Industriale, Università degli Studi di Padova, Padova, Italy \\ ${ }^{\mathrm{b}}$ Dipartimento di Elettronica, Informazione e Bioingegneria, Politecnico di Milano, Milano, Italy
}

\begin{abstract}
The response of cantilevered piezoelectric harvesters loaded by finite width impulses of base acceleration is studied analytically in the frequency domain in order to identify the parameters that influence the generated voltage. Experimental tests are then performed on harvesters loaded by hammer impacts. The latter are used to confirm analytical results and to validate a linear finite element (FE) model of a unimorph harvester. The FE model is, in turn, used to extend analytical results to more general harvesters (tapered, inverse tapered, triangular) and to more general impulses (heel strike in human gait). From analyt-ical and numerical results design criteria for improving harvester performance are obtained.
\end{abstract}

\section{Introduction}

In recent years piezoelectric harvesters have proved to be able to transform kinetic energy of vibrations into electrical energy that can be used to feed sensors and other small electronic devices. Many applications have been proposed in the fields of automotive engineering [1], monitoring of structures and machines [2], bioengineering [3], sport apparel and equipment [4], and efficient commercial piezoelectric harvesters are now available.

Multi-physics mathematical simulations and experimental results $[5,6]$ show that a piezoelectric harvester generates the maximum electric power in resonance condition, when the natural frequency of the harvester is tuned to the frequency of ambient vibrations; performance strongly decreases when the harvester does not operate in resonance. If ambient vibrations are dominated by an harmonic component at constant frequency, the harvester can be tuned accordingly prior to its installation on the vibrating structure [5]. However, harmonic vibrations with variable frequency, usually found in vehicles running at different speeds [1,7] or in household appliances driven by electric motors equipped with inverters, require a continuous tuning of the harvester or a wide band harvester [8] able to effectively convert kinetic energy into electrical energy in the whole frequency band between the maximum and minimum frequencies of operation [5].

Harmonic vibrations are important, but they represent only a particular class of ambient vibrations. Given the need for harvesters to collect periodic, impulsive or random vibrations, it is necessary to adopt specific technical solutions to tune them or widen their operation band [9].

\footnotetext{
* Corresponding author.

E-mail address: alberto.doria@unipd.it (A. Doria).
} 
This research focuses on the problem of harvester tuning in the presence of impulsive vibrations, which may be found in nature [10,11], or during machine operation [12]. Moreover some recent studies on the problem of energy harvesting from low frequency vibrations $(1-30 \mathrm{~Hz}$ ) proposed a frequency up-conversion that is based on devices capable of generating series of impacts from low frequency motions [13]. Thus the interest in impulsive excitation is increasing. The problem of collecting kinetic energy from impulsive vibrations by means of harvesters has been addressed in the literature for a decade. In [14] a cantilever piezoelectric harvester was optimized to collect energy from impulses whose duration was very short compared to the natural period of the harvester. The analysis was carried out by means of a lumped element network model. Optimized values of load resistance and thickness ratio (between the piezoelectric material and the structural material) were found. Short duration impulses were also considered by Wei et al. in [15]. In [16] the energy harvesting performance of a piezoelectric stack under shock events was investigated. In this case the duration of the impulses was very long compared to the natural period of the harvester. A lumped element model of the harvester was developed and numerical results in the time domain showed a good agreement with experimental results. The impulse duration can be comparable with the natural period of the harvester in many energy harvesting applications such as intelligent tires $[12,17]$ and energy harvesting from human motion [18,19]. In [17] an impulsive method for testing piezoelectric harvesters for tires was developed. Preliminary results showed the effect of impulse duration on the harvester's performance. The impact harvester investigated in [20] was studied in the time domain and finite duration impacts were described through a Hertzian contact law. In [21] the response of a piezoelectric harvester to finite width impulses modeled as Gaussian functions was investigated. The effect of various parameters on the harvester's performance was studied. Numerical results showed large variations in the performance when the impulse duration changed from values shorter than the natural period of the harvester to values longer than the natural period of the harvester.

This paper aims at studying the effects of the shape and duration of a finite width impulse on the performance of a cantilever harvester, using analytical, experimental and numerical methods. A one degree of freedom (DOF) model of a cantilever harvester excited by ideal impulses is considered and a frequency domain approach similar to the one used to study the shock response of structures [22] is adopted. Analytical results show that it possible is to exploit the relation between impulse duration and harvester natural period to ultimately maximize the harvester's performance.

Experimental tests corroborate the analytical model, show that the maximum excitation condition holds for cantilevered unimorph and bimorph harvesters loaded with impacts generated by a hammer for modal testing.

A 3D multi-physics finite element (FE) model of a rectangular unimorph harvester is then developed in COMSOL. Both frequency and time domain responses to impacts are validated by means of experimental tests. The validated FE model is used to develop various models of cantilever harvesters having the same layers and piezoelectric properties but different geometries (tapered, inverse tapered, triangular).

Numerical results obtained by means of these models show that a harvester of assigned geometry, stiffness and mass can be excited in the best way by an impulse of base acceleration only if the impulse has a certain shape and duration. If the characteristics of the impulse are assigned, some different solutions (geometry, added mass) can be found to design a harvester that can be excited in the best way.

Finally the response of various harvesters to a more complex impulse of practical interest is simulated: the acceleration impulse caused by heel strike in human gait. Numerical results show that a maximum excitation condition can be found for this impulse as well.

\section{Harvester response to a finite width impulse}

A piezoelectric harvester converts mechanical energy into electrical energy. The harvester is typically connected to an electric circuit for power extraction. In the framework of this research open circuit voltage $v_{o c}(t)$ is used as a reference parameter since it is an important variable for the design of the electric circuit [23].

In Fig. 1 the equivalent electric circuit for the harvester in open circuit condition is represented in the frequency domain: $\omega$ is the angular frequency, $I(\omega)$ is the current generated by the piezoelectric layer, $C_{p u}$ is the internal capacitance of the piezoelectric layer.

In the frequency domain, the open circuit voltage is related to the mechanical excitation through this equation:

$$
V_{o c}(\omega)=F R F(\omega) F_{r}(\omega)
$$

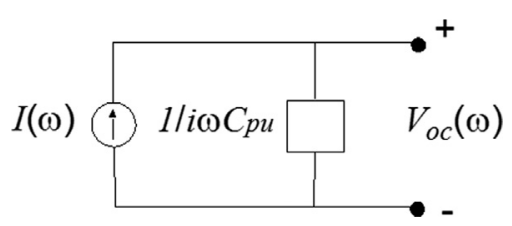

Fig. 1. Equivalent circuit of the harvester. 
where $V_{o c}(\omega)$ is the spectrum of the open circuit voltage. The harvester is represented by a single-mode model, as in most studies dealing with harvesters loaded by impacts [13,14]. Numerical results reported in [17] showed that the effects of higher order modes can be neglected. Therefore, with the above-mentioned assumption, $F R F(\omega)$ is the frequency response function of the 1 DOF model of the unimorph harvester, as derived in [6]:

$$
F R F(\omega)=\frac{\varphi_{r}^{u}}{C_{p u}\left(\omega_{r}^{2}-\omega^{2}+2 i \zeta_{r} \omega_{r} \omega\right)+\varphi_{r}^{u} \chi_{r}^{u}}
$$

In (2) $\omega_{\mathrm{r}}$ is natural frequency, $\zeta_{\mathrm{r}}$ is the damping ratio of the fundamental mode $(r), \varphi_{r}^{u}$ is the forward modal coupling coefficient, $\chi_{r}^{u}$ is the backward modal coupling coefficient and $C_{p u}$ is the capacitance.

$F_{r}(\omega)$ is the spectrum of the modal forcing function, which depends on the base acceleration [6] as follows:

$$
F_{r}(\omega)=A_{\text {in }}(\omega) m \int_{0}^{L} \phi_{r}(x) d x
$$

In (3) $A_{\text {in }}(\omega)$ is base acceleration, $m$ is the mass per unit length and $\phi_{r}(x)$ is the modal shape of the fundamental mode. It should be noted that $m$ and $\int_{0}^{L} \phi_{r}(x) d x$ are constants that scale the base acceleration impulse but do not change the frequency content.

The response of the harvester is maximized when the impulse excites the harvester at its natural frequency. To further analyze this concept, ideal impulses are considered.

In Fig. 2 a half-sine force impulse with duration $\tau$ and maximum amplitude $F_{0}$ is considered. $F_{r}(\omega)$ is given by the following equation:

$$
F_{r}(\omega)=F_{o} \frac{\pi \tau(\cos (\omega \tau)-i \sin (\omega \tau)+1)}{\pi^{2}-\tau^{2} \omega^{2}}
$$

The amplitude of this function is plotted in Fig. 3. It has the main peak for $\omega=0$, and its value $2 F_{0} \tau / \pi$ decreases when duration $\tau$ decreases. At higher frequencies there are minor peaks separated by minima, and the first minimum takes place when $\omega_{c}=3 \pi / \tau$.

The amplitude of the impulse spectrum at the natural frequency of the harvester $\left(\omega_{r}\right)$ can be calculated by setting $\omega=\omega_{r}$ in Eq. (4). The result of this calculation is plotted in Fig. 4 as a function of the normalized impulse duration $\left(\tau_{\text {norm }}\right)$, which is the ratio between $\tau$ and the natural period of the harvester $T_{r}=2 \pi / \omega_{\mathrm{r}}$. A piezoelectric harvester with $T_{r}=8 \mathrm{~ms}$ is considered.

Fig. 4 clearly shows that the optimal excitation condition corresponds to $\tau / T_{n}=0.675$. Conversely, the first minimum takes place when $\tau_{\text {norm }}=1.5$.

Sometimes real impulses do not vary as sharply as the half-sine impulse, and the real phenomenon can be modeled as a shifted-cosine impulse, which is described by Eq. (5) and is presented in Fig. 2.

$$
f_{r}(t)= \begin{cases}F_{o} \frac{\left(1-\cos \left(\frac{2 \pi}{\tau} t\right)\right)}{2} & 0 \leqslant t \leqslant \tau \\ 0 & t<0 \cup t>\tau\end{cases}
$$

The Fourier transform of this function is given by Eq. (6) and its amplitude is plotted in Fig. 3.

$$
F_{r}(\omega)=F_{o} \frac{2 \pi^{2}(i \cos (\omega \tau)+\sin (\omega \tau)-i)}{\omega\left(4 \pi^{2}-\tau^{2} \omega^{2}\right)}
$$

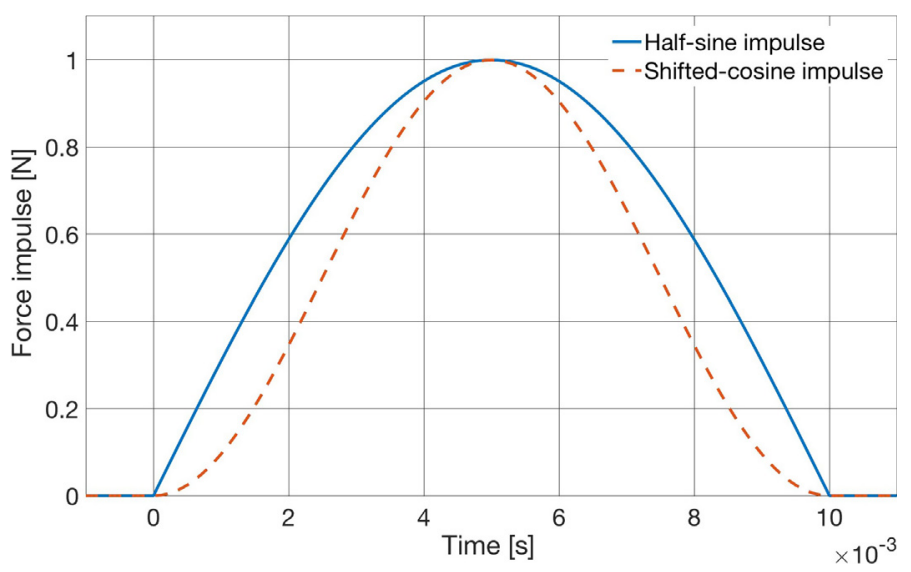

Fig. 2. Ideal impulses: solid line half-sine impulse, dashed line shifted-cosine impulse ( $\tau=0.01 \mathrm{~s} F_{o}=1 \mathrm{~N}$ ). 


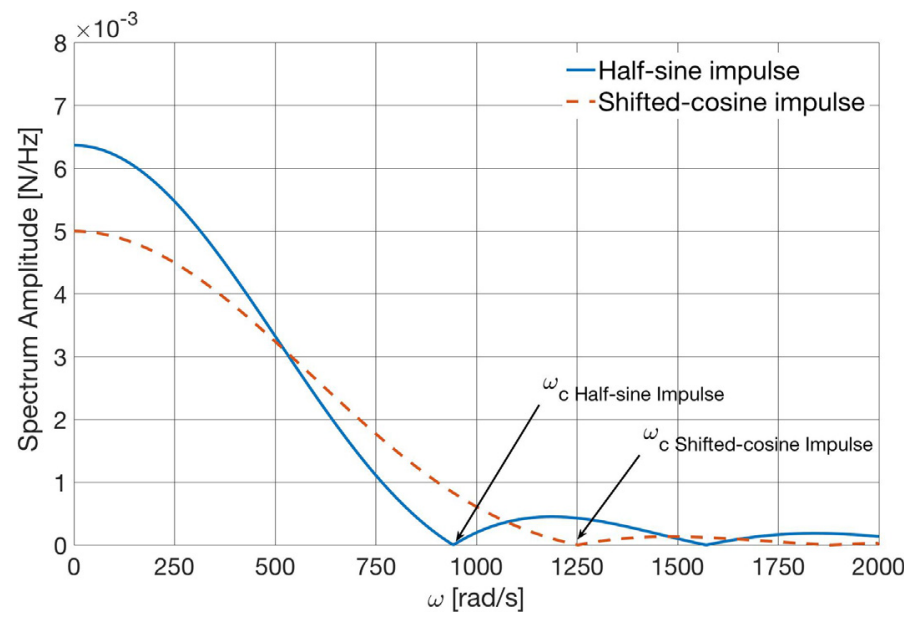

Fig. 3. Spectra (amplitudes) of ideal impulses: solid line half-sine impulse, dashed line shifted-cosine impulse $\left(\tau=0.01 \mathrm{~s} F_{o}=1 \mathrm{~N}\right)$.

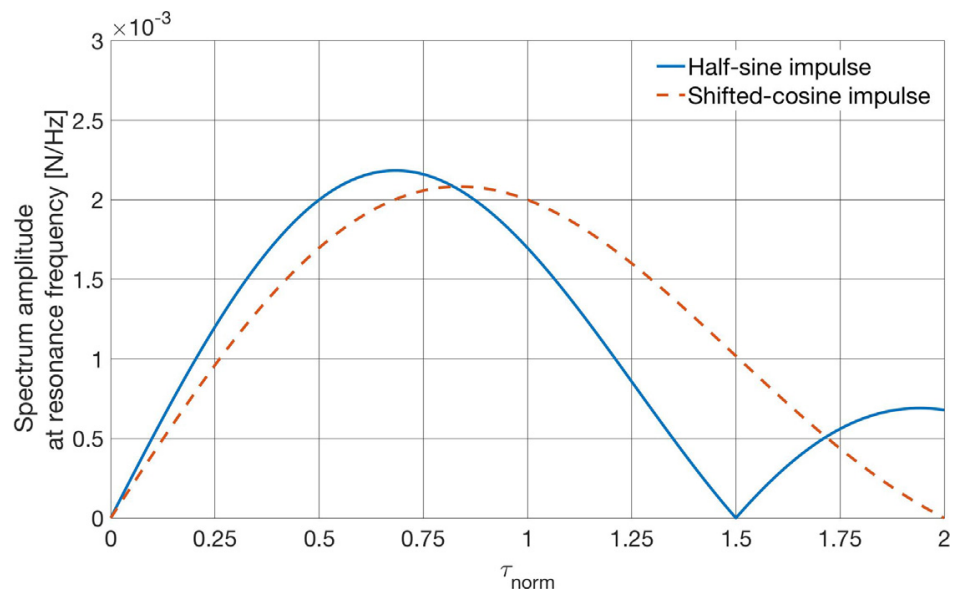

Fig. 4. Maximum response condition: solid line half-sine impulse, dashed line shifted-cosine impulse.

The maximum value is $F_{o} \tau / 2$ and the first minimum takes place for $\omega_{c}=4 \pi / \tau$. In this case the amplitude of the impulse at the natural frequency of the harvester reaches the maximum value when $\tau_{\text {norm }}=0.8375$.

So far the harvester with its natural period has been assigned, but in many practical situations the impulse duration is given and the harvester that maximizes performance has to be found. Also in this case the frequency domain analysis is useful in the harvester's design process.

A first effect is highlighted by the spectra of ideal impulses (Fig. 3). They clearly show that, in order to collect a large amount of energy, the resonance peak of the harvester has to belong to the frequency band $\left[0, \omega_{c}\right]$ in which $\omega_{c}$ is the angular frequency of the first minimum of the spectrum. When this condition is satisfied, the lower the natural frequency the larger is the amount of energy that can be collected.

A second effect is due to the FRF between the generated voltage and the base excitation (Eq. (2)). The peak of the FRF in resonance condition is given by:

$$
\operatorname{FRF}\left(\omega_{r}\right)=\frac{\varphi_{r}^{u}}{C_{p u} 2 i \zeta_{r} \omega_{r}^{2}+\varphi_{r}^{u} \chi_{r}^{u}}
$$

And in terms of natural period $\left(T_{r}=2 \pi / \omega_{r}\right)$ :

$$
F R F\left(T_{r}\right)=\frac{\varphi_{r}^{u}}{C_{p u} 2 i \zeta_{r}\left(\frac{2 \pi}{T_{r}}\right)^{2}+\varphi_{r}^{u} \chi_{r}^{u}}
$$




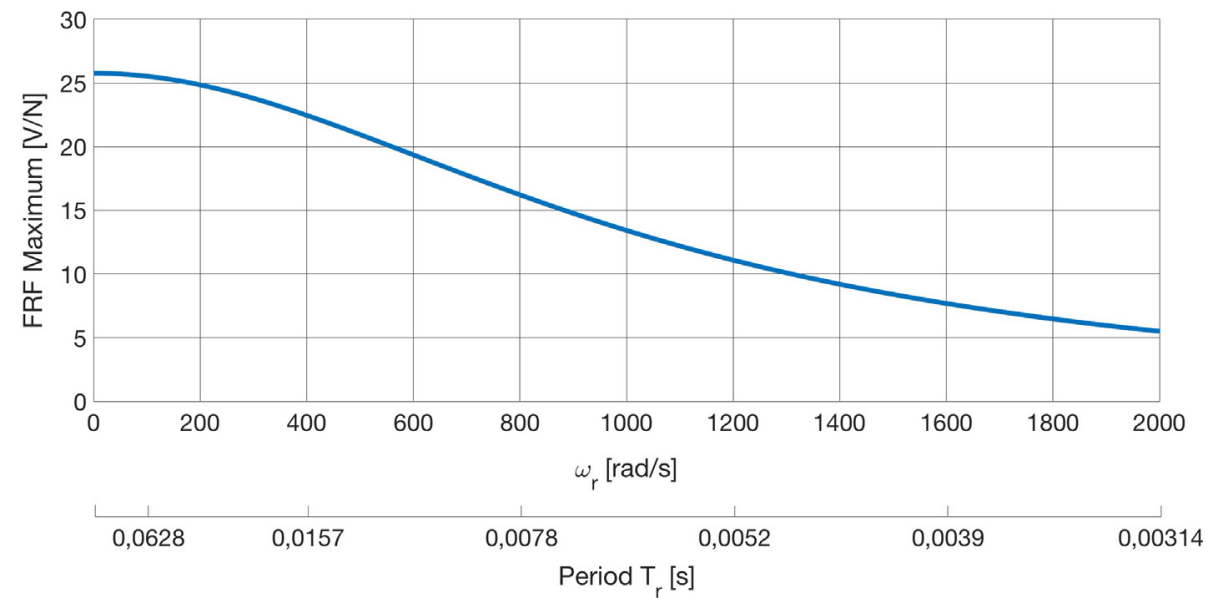

Fig. 5. Maximum value of FRF amplitude against tuning frequency and period.

Fig. 5 shows that the peak of the FRF increases when the natural frequency of the harvester decreases [24]. The slope of the curve decreases at low frequencies, when at the denominator of the FRF the term containing the forward and backward coefficients becomes important.

The maximum value of the output spectrum $V_{o c}(\omega)$ is the product of the FRF in resonance condition (Eq. (7)) and the corresponding line $\left(\omega=\omega_{r}\right)$ of input spectrum. The result of this calculation for an half-sine impulse is shown by the threedimensional (3D) surface plot in Fig. 6. It represents the maximum value of the amplitude of the output spectrum against natural period $T_{r}$ and impulse duration $\tau$.

An intersection of the 3D surface with a vertical plane $\tau=$ constant confirms that an impulse of given duration $\tau$ can be exploited in the best way by increasing the natural period of the harvester (i.e. lowering the natural frequency). When the impulse is very short, the maximum peak of the response increases in monotonic fashion when the natural period increases. When the impulse is long and the natural period increases, there is first a zone of the 3D surface with maxima and minima and then there is a second zone in which the maximum peak of the response increases monotonically. The separation between the two zones takes place at $T_{r}=1.5 \tau$.

It is worth noting that, if an intersection of the 3D surface with a plane $T_{r}=$ constant (assigned harvester) is considered, the maximum response condition of Fig. 4 is retrieved.

Similar results can be obtained considering the shifted-cosine impulse.

An increase in the natural period (i.e. the reduction in the natural frequency) improves the performance of the harvester, but it has an important drawback, which is mathematically described by the FRF between transverse displacement of the cantilever $w_{\text {rel }}$ (relative to the moving base) and base excitation [6]:

$$
\frac{w_{r e l}(\omega)}{F_{r}(\omega)}=\frac{C_{p u} \phi_{r}(x)}{C_{p u}\left(\omega_{r}^{2}-\omega^{2}+2 i \zeta_{r} \omega_{r} \omega\right)+\varphi_{r}^{u} \chi_{r}^{u}}
$$

This FRF clearly shows that, if the natural frequency decreases, the displacement in resonance increases proportionally to $1 / \omega_{\mathrm{r}}^{2}$ inducing mechanical stresses that can potentially destroy the harvester or significantly reduce its operative life. In con-

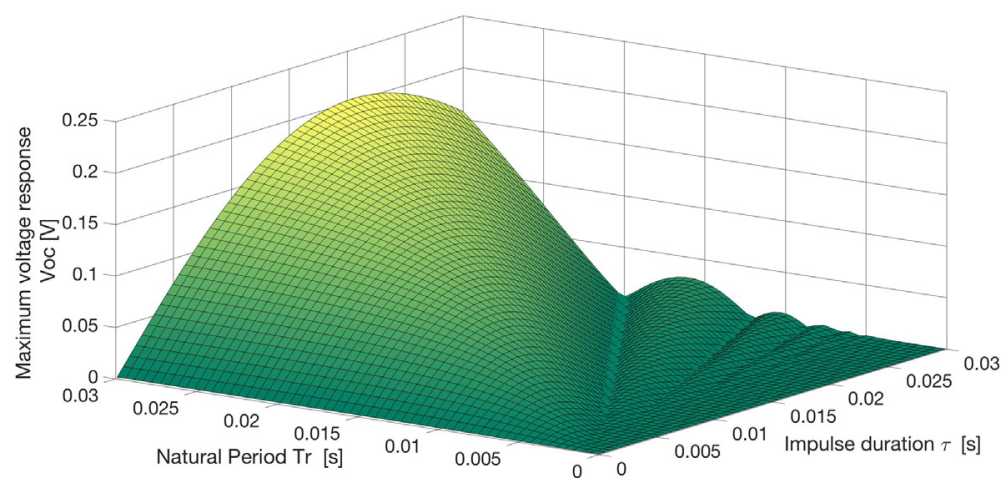

Fig. 6. Maximum amplitude of the response $\left(V_{o c}\right)$ of the harvester in the frequency domain vs. natural period $T_{r}$ and impulse duration $\tau$ (half-sine impulse). 
clusion a detailed FE multi-physics analysis is needed to find the harvester's natural frequency (i.e. natural period) that represents a good trade-off between the increase in generated voltage and the increase in mechanical stresses.

\section{The impulsive testing method}

A specific test rig for cantilever harvesters with length of some tens of millimeters was developed [17]. The main component of the test rig is an aluminum bar suspended from a frame by means of ropes, which isolate the system from the vibrations of the surroundings. The harvester is clamped at one end of the aluminum bar and an hammer for modal testing is used to hit the opposite end of the bar (Fig. 7). In this way the hammer impact generates longitudinal vibrations inside the aluminum bar that, in turn, generate the acceleration impulse at the base of the harvester. The duration of the force impulse and consequently the duration of the acceleration impulse at the base of the harvester depends on the resilience of the hammer tip. Different impulse widths can be obtained using hammer tips with different resilience [25]. Usually hammers for modal testing are equipped with a series of tips.

The measurement equipment includes a small piezoelectric accelerometer mounted on the clamped base of the cantilever (Fig. 7) and a piezoelectric load cell mounted on the head of the hammer for modal testing. The signals of the sensors and the voltage generated by the harvester are acquired by means of a NI 9234 board. Digital signals are analyzed in the time and frequency domains by means of NI Signal Express. In particular the FRF (between generated voltage and base acceleration) and the spectrum of the hammer impact are calculated. Some preliminary tests were carried out to validate the test rig and good repeatability and accuracy were found [17].

\section{Experimental results}

Most of experimental tests were carried out on a MIDE PPA 1001 harvester. It is a general-purpose unimorph harvester having a rectangular shape ( $41.1 \mathrm{~mm}$ length, $20.8 \mathrm{~mm}$ width) with a PZT 5H piezoelectric layer (thickness $0.15 \mathrm{~mm}$ ), a stainless steel 304 structure (thickness $0.15 \mathrm{~mm}$ ) and a copper electrode (thickness $0.03 \mathrm{~mm}$ ). The upper side is covered by polyester (thickness $0.05 \mathrm{~mm}$ ) the lower side is covered by polyimide (thickness $0.03 \mathrm{~mm}$ ). The nominal natural frequency of this harvester is $130 \mathrm{~Hz}$, which corresponds to a natural period of $7.7 \mathrm{~ms}$. Some tests were carried out also on a MIDE V22B harvester. It is a bimorph cantilevered harvester with $35.6 \mathrm{~mm}$ length, $6 \mathrm{~mm}$ width and $0.8 \mathrm{~mm}$ thickness.

The harvesters were tested by means of impulses of different duration and the duration was varied by changing the tip of the hammer of the harvester. Impulses with durations ranging from 1 to $16 \mathrm{~ms}$ were obtained.

Fig. 8 shows experimental results in the frequency domain. The measured FRF between generated voltage and base acceleration shows a peak at $125 \mathrm{~Hz}\left(\omega_{\mathrm{r}}=2 \pi 125\right)$. The damping ratio of the harvester $(\zeta)$ can be evaluated by means of the half power method [26], considering the two frequencies $\left(\omega_{1}, \omega_{2}\right)$ corresponding to FRF amplitudes equal to 0.707 the peak value:

$$
\zeta=\frac{\omega_{2}-\omega_{1}}{2 \omega_{r}}
$$

The calculated damping ratio is $\zeta=0.08$.

Since there is only one resonance peak, Fig. 8 suggests that only the first bending mode is involved in the voltage generation caused by the base acceleration impulse. The spectra of two hammer impulses are represented in Fig. 8 as well. The

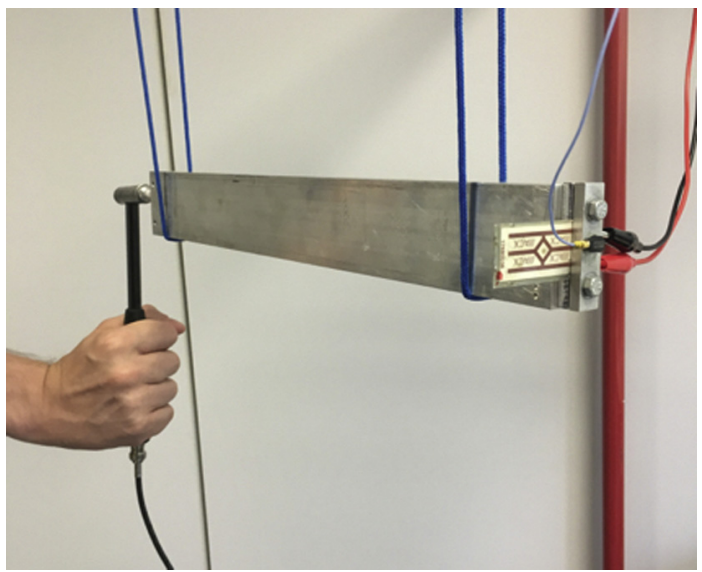

Fig. 7. Test rig. 


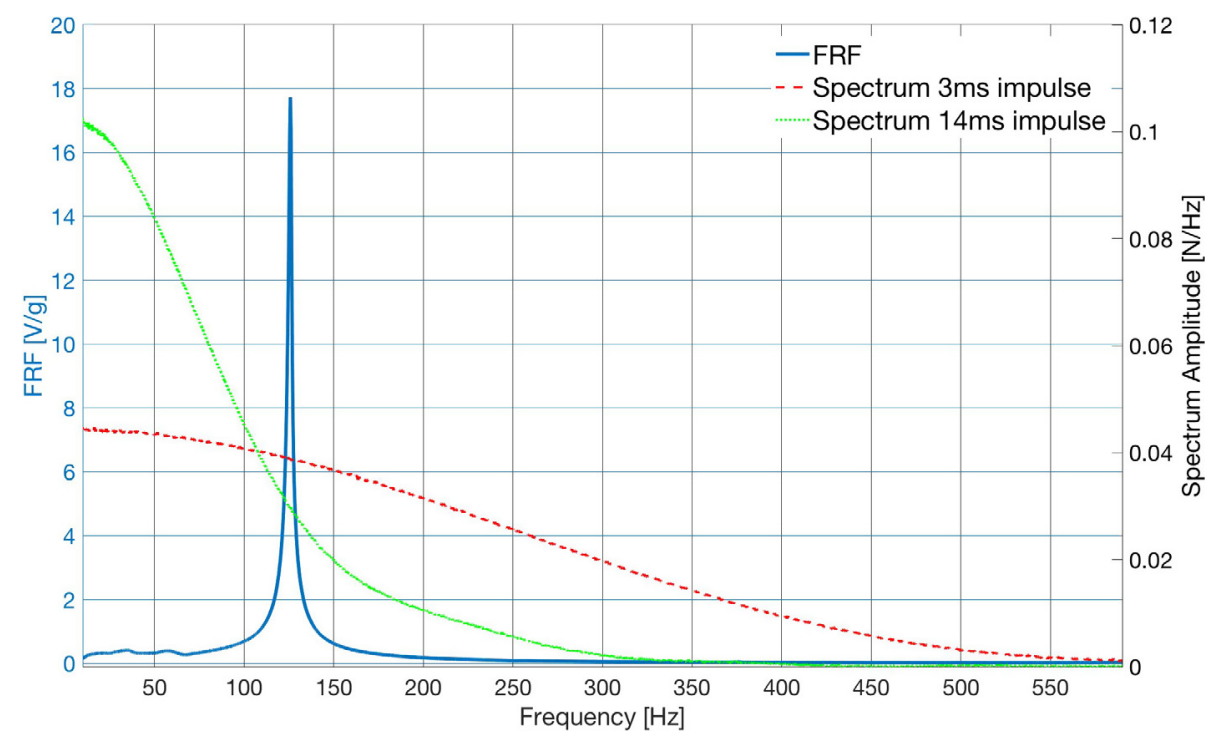

Fig. 8. FRF of PPA1001 harvester and spectra of impulses.

impulse with duration $\tau=3 \mathrm{~ms}$ shows a large amplitude (close to the maximum value) at the harvester's resonance frequency; whereas the impulse with a longer duration $(\tau=14 \mathrm{~ms})$ shows a smaller amplitude at the resonance frequency.

Fig. 9 shows experimental results in the time domain obtained when the PPA1001 harvester is excited by impulses of different duration $\tau$. The base acceleration impulses are similar to the force impulses. A detailed analysis of the acceleration impulses, which is shown in Fig. 10, reveals that they are not perfectly symmetric and are more similar to shifted-cosine impulses rather than to an half-sine impulses. The generated voltage is a damped oscillation. With $\tau=3$ ms the generated voltage does not reach the maximum value during the impulse, but in the first cycle of free oscillations. Whereas, with $\tau=14 \mathrm{~ms}$, the generated voltage reaches the maximum amplitude during the impulse and the free damped oscillations have a smaller amplitude.

Preliminary experimental results dealing with the effect of impulse duration on the generated voltage were presented in [17]. In the framework of the present research, an extended series of tests was performed both on PPA 1001 and V22B. Table 1 summarizes the experimental results.
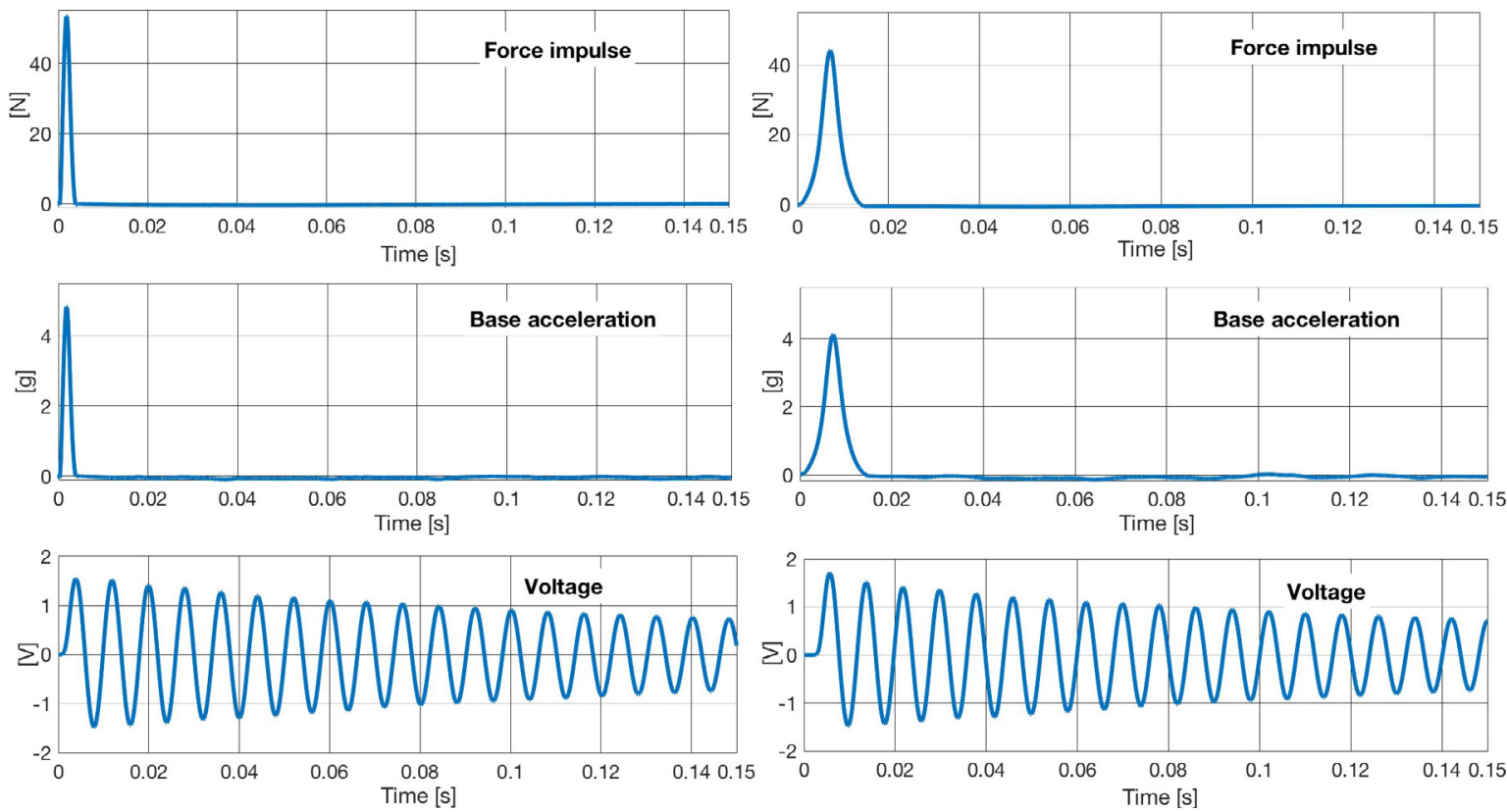

Fig. 9. Impulsive force, base acceleration and time response of PPA1001 harvester, $\tau=3 \mathrm{~ms}$ (left) and $\tau=14 \mathrm{~ms}$ (right). 

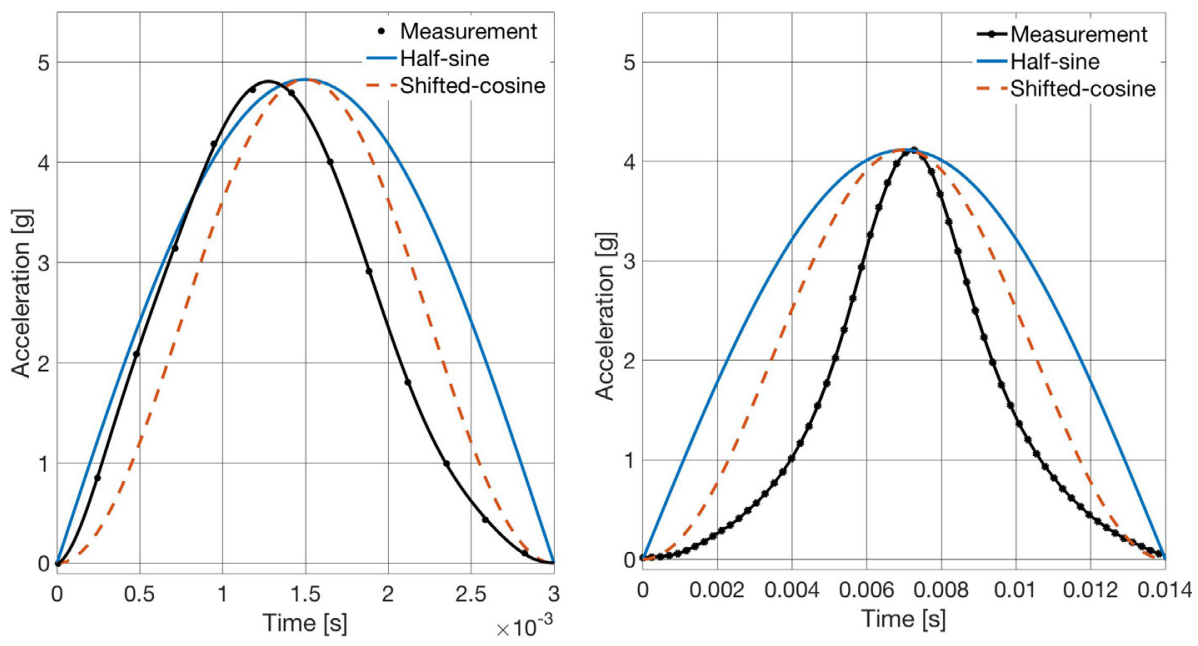

Fig. 10. Base acceleration, actual impulse and ideal impulses, $\tau=3 \mathrm{~ms}$ (left) and $\tau=14 \mathrm{~ms}$ (right).

Two parameters are used for ranking the performance of the harvesters. The first is the maximum peak-to-peak voltage generated after the end of the impulse $\left(v_{p p}\right)$ : it represents the amplitude of free oscillations, which collect most of energy. The second is the maximum (positive or negative) peak voltage during the impulse $\left(v_{m i}\right)$; the maximum value is considered instead of the peak-to-peak value, since, with short impulses, there is not a complete cycle of oscillation during the impulse itself (Fig. 9). Both parameters are divided by the base acceleration peak $\left(a_{c}\right)$. Each test was repeated five times and Table 1 summarizes the mean values and the coefficients of variation of the measurements.

Even if actual harvesters are distributed parameter systems and actual impulses are different from ideal impulses, Table 1 shows that the maximum peak-to-peak voltage is generated when the impulse duration is close to the optimal value found for ideal shifted-cosine impulses $\left(\tau_{\text {norm }}=0.8375\right.$ ). When the impulse duration is much shorter than the optimal value, $v_{m i}$ (during the impulse) is smaller than $0.5 v_{p p}$ (after the impulse); when the impulse duration is larger than the optimal value, $v_{m i}$ can be much larger than $0.5 v_{p p}$. Harvester V22B generates less voltage than PPA1001, because its natural frequency is higher.

\section{Numerical model}

The 3D numerical FE model of the unimorph harvester was developed by means of COMSOL [27]. The multi-physics linear model includes mechanical, electrostatic and electrical equations and takes into account geometrical and structural details, like the layers of different materials and the edges of the plastic material that surrounds the active area of the piezoelectric material.

Table 1

Experimental results in the time domain.

\begin{tabular}{|c|c|c|c|c|c|c|c|}
\hline \multirow[t]{2}{*}{ Harvester } & \multirow[t]{2}{*}{$T_{r}[\mathrm{~ms}]$} & \multicolumn{2}{|l|}{$\tau_{\text {norm }}$} & \multicolumn{2}{|l|}{$\left(\frac{v_{p p}}{a_{c}}\right)$} & \multicolumn{2}{|l|}{$\left(\frac{v_{m i}}{a_{c}}\right)$} \\
\hline & & Mean value & $\begin{array}{l}\text { Coefficient of } \\
\text { variation }\end{array}$ & $\begin{array}{l}\text { Mean value } \\
{[\mathrm{V} / \mathrm{g}]}\end{array}$ & $\begin{array}{l}\text { Coefficient of } \\
\text { variation }\end{array}$ & $\begin{array}{l}\text { Mean value } \\
{[\mathrm{V} / \mathrm{g}]}\end{array}$ & $\begin{array}{l}\text { Coefficient of } \\
\text { variation }\end{array}$ \\
\hline PPA 1001 & 8.0 & 0.08 & 0.046 & 0.171 & 0.089 & 0.017 & 0.037 \\
\hline PPA 1001 & 8.0 & 0.40 & 0.031 & 0.608 & 0.035 & 0.310 & 0.036 \\
\hline PPA 1001 & 8.0 & 0.50 & 0.034 & 0.653 & 0.044 & 0.344 & 0.039 \\
\hline PPA 1001 & 8.0 & 0.73 & 0.024 & 0.745 & 0.041 & 0.387 & 0.045 \\
\hline PPA 1001 & 8.0 & 0.80 & 0.034 & 0.790 & 0.028 & 0.412 & 0.027 \\
\hline PPA 1001 & 8.0 & 0.99 & 0.028 & 0.760 & 0.023 & 0.401 & 0.028 \\
\hline PPA 1001 & 8.0 & 1.30 & 0.033 & 0.742 & 0.017 & 0.405 & 0.019 \\
\hline PPA 1001 & 8.0 & 1.75 & 0.021 & 0.569 & 0.044 & 0.387 & 0.005 \\
\hline PPA 1001 & 8.0 & 2.11 & 0.025 & 0.210 & 0.136 & 0.343 & 0.030 \\
\hline V22B & 3.7 & 0.18 & 0.067 & 0.174 & 0.059 & 0.069 & 0.159 \\
\hline V22B & 3.7 & 0.58 & 0.041 & 0.295 & 0.035 & 0.104 & 0.040 \\
\hline V22B & 3.7 & 0.89 & 0.033 & 0.358 & 0.027 & 0.127 & 0.036 \\
\hline V22B & 3.7 & 1.06 & 0.058 & 0.321 & 0.053 & 0.116 & 0.063 \\
\hline V22B & 3.7 & 1.69 & 0.014 & 0.131 & 0.065 & 0.110 & 0.024 \\
\hline V22B & 3.7 & 2.04 & 0.022 & 0.050 & 0.084 & 0.081 & 0.035 \\
\hline
\end{tabular}




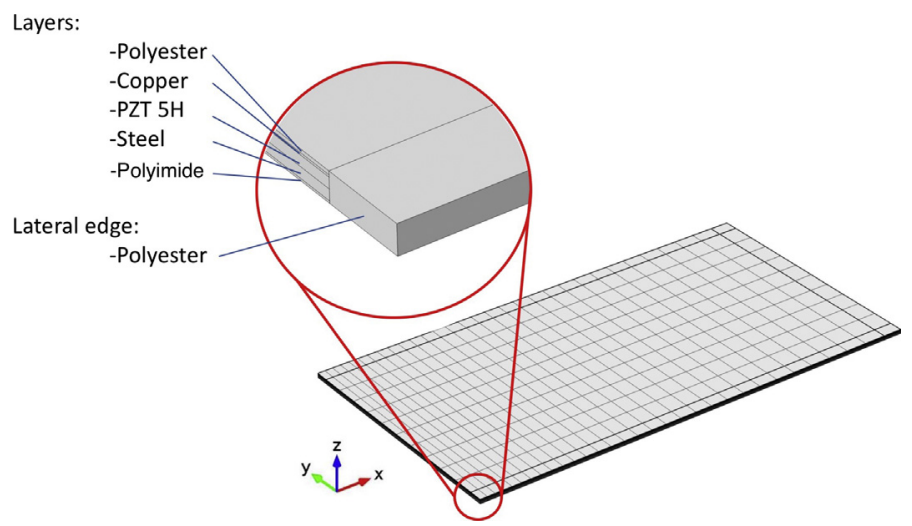

Fig. 11. FE model of the unimorph piezoelectric harvester with the different layers.

Table 2

Numerical results, natural frequencies and resonance peaks of PPA1001.

\begin{tabular}{|c|c|c|c|}
\hline \multirow[t]{2}{*}{ Mode number } & \multirow{2}{*}{$\begin{array}{l}\text { Eigenvalue analysis } \\
\text { Frequency [Hz] }\end{array}$} & \multicolumn{2}{|c|}{ Harmonic response analysis } \\
\hline & & Frequency [Hz] & FRF peak $[\mathrm{V} / \mathrm{g}]$ \\
\hline 1 & 121.3 & 125.4 & 18.27 \\
\hline 2 & 500.5 & - & - \\
\hline 3 & 752.4 & 763.2 & 0.670 \\
\hline 4 & 1627 & - & - \\
\hline 5 & 2104 & 2129 & 0.078 \\
\hline
\end{tabular}

The PPA1001 unimorph cantilever is composed of 5 layers of different and perfectly bonded materials. One layer is made of piezoelectric material and the other 4 are the substrate (steel, copper, polyimide and polyester).

The substrate materials were simulated as a linearly elastic materials with isotropic properties; conversely, the piezoelectric material was modeled as a transverse isotropic linear elastic material with its polarization axis perpendicular to the layer. The materials' characteristics and dimensional properties used in the model are summarized in Appendix A.

To improve the reliability of the simulations, a detailed 3D mesh was developed (Fig. 11). The piezoelectric layer was simulated by means of 5 elements in the thickness direction and by 30 elements and 10 elements in the directions of length and width, respectively. All the characteristics of the mesh were defined in a parametric way that makes possible quick variations in the geometry of the harvester.

An eigenvalue analysis was carried out in the mechanical domain, since there is a small effect of backward coupling on the modal parameters. Then a modal order reduction was adopted and the steady state harmonic response was calculated in the multi-physics domain. In this simulation a hysteretic damping model with a hysteretic damping factor equal to $\eta=2 \zeta=0.016$ (where $\zeta$ is the damping ratio) was used. Table 2 shows that there is a very small difference between the natural frequencies found with the eigenvalue analysis (mechanical model) and the resonance frequencies found with the harmonic response analysis using the complete multi-physics model. It is worth mentioning that in the harmonic response analysis the second and fourth vibration modes are not identified, since they are torsional modes and do not generate electric voltage due to their anti-symmetrical shapes.

Finally, a transient analysis in the time domain was carried out considering the complete multi-physics model. For this analysis a Rayleigh damping model was adopted, owing to the characteristics of the solution method of COMSOL [27].

\section{Validation of numerical model}

The numerical model was validated simulating the experimental tests carried out on the PPA1001 harvester. Both the numerical frequency response and the time response were validated. Fig. 12 makes a comparison between numerical and experimental FRFs (between open circuit voltage and base acceleration). It shows that the numerical model is able to reproduce the measured FRF with a very small error ( $2 \%$ in the peak value).

Fig. 13 shows that the reproduction of the time domain experimental results is more difficult. This is due to the fact that, if the measured impulse is modeled as a half-sine impulse with the same maximum amplitude and duration as the hammer impulse, large errors in the generated voltage appear during the first cycles of oscillation. The quality of the simulation increases if the actual impulse is modeled as a shifted-cosine impulse. The difference between numerical and experimental results becomes very small when the impulse simulated in the FE model is a polynomial fit of the measured acceleration impulse. 


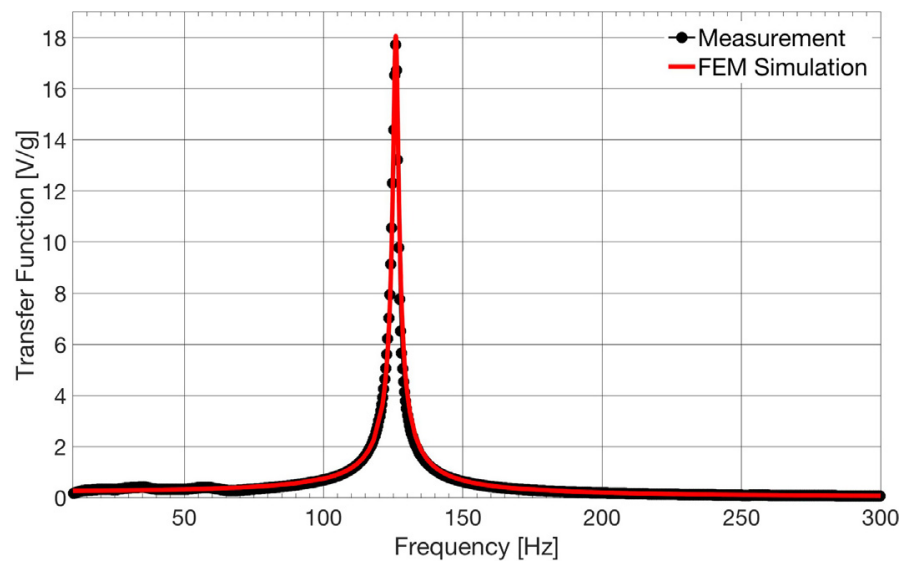

Fig. 12. Comparison between numerical and experimental FRFs.

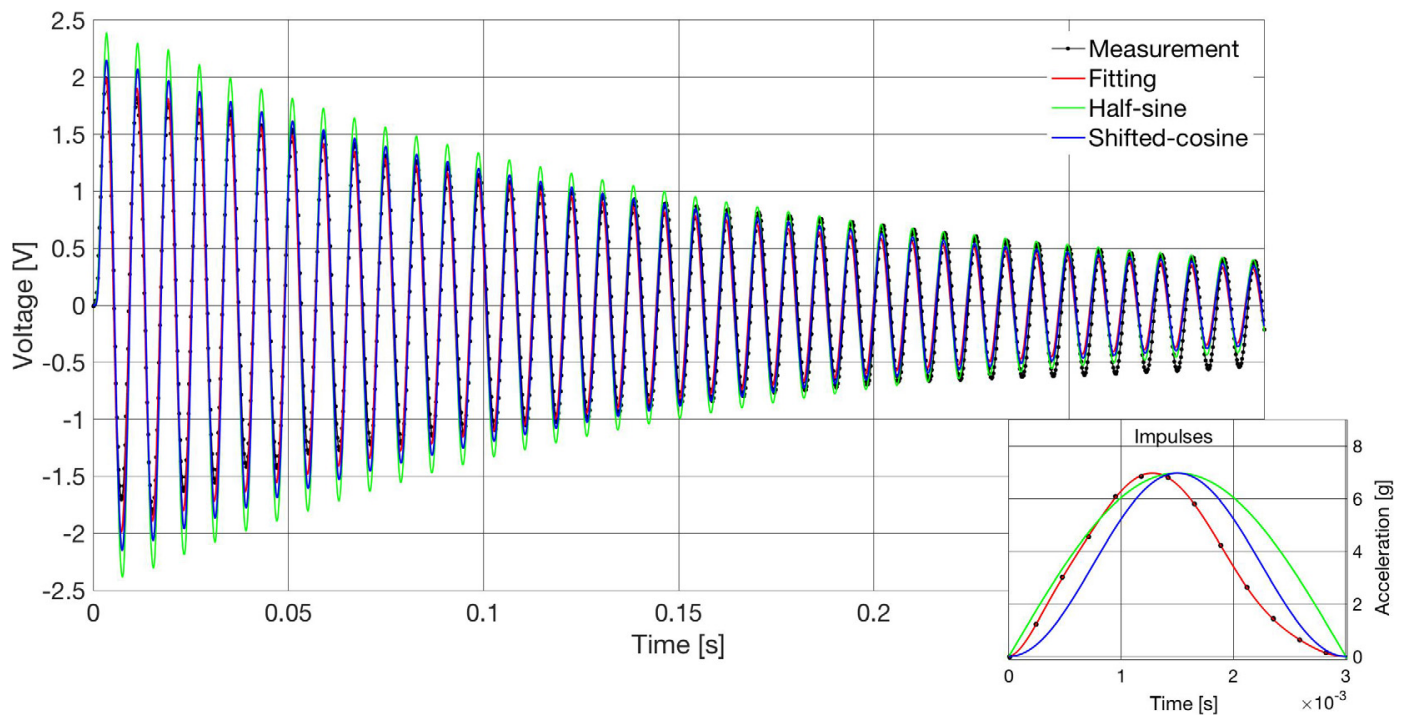

Fig. 13. Comparison between numerical and experimental time response, short impulse ( $3 \mathrm{~ms}$ ).

\section{Numerical results}

Numerical simulations of the performance of several kinds of harvesters derived from the unimorph harvester PPA1001 were carried out in order to verify that the optimal excitation conditions, that were previously computed analytically for an ideal harvester, hold true for harvesters of different shapes as well. After a literature survey of recently proposed harvester designs [28-31], six harvesters were considered:
a. PPA 1001;
b. PPA 1001 with tip mass $(0.59 \mathrm{~g})$;
c. Wide rectangular;
d. Tapered;
e. Inverse tapered;
f. Triangular.

Some authors [28] highlighted that a correct comparison between harvesters with different geometries requires a clear definition of the design parameters. For this reason, in the presented numerical simulations the cross section of the various harvesters and the volume of the piezoelectric material were kept equal to the ones of PPA1001. Therefore, when the width at the clamped end $\left(b_{c}\right)$ and/or the width at the free end $\left(b_{e}\right)$ were varied, the harvester's length (L) was varied accordingly, these dimensions refer to the active part of the harvester, covered by piezoelectric material. 


\subsection{Numerical modal analysis}

A preliminary numerical modal analysis was carried out to find the natural frequencies and modes of vibration of the various harvesters. Numerical results are summarized in Table 3.

On the one hand a significant decrease in the first natural frequency can be achieved by adding a tip mass (0.59 g) or by using the inverse tapered and triangular shapes. On the other hand, the wide rectangular shape and the tapered shape lead to increases in the first natural frequency. In all the harvesters hereby considered, the first mode is a simple bending mode with a node at the fixed end. The torsional mode cannot be excited by a uniform base acceleration. The higher order bending modes are characterized by strain nodes with sign alternations along the harvester length, which lead to cancellations in the generated voltage, if a continuous electrode is adopted [32].

\subsection{Half-sine impulses}

After the mentioned numerical modal analysis, time domain analyses were carried out to analyze the dependence of the maximum peak-to-peak voltage generated by the harvester on the duration of the impulse. Half-sine impulses of amplitude $a_{c}=1 \mathrm{~g}$ and different duration $\tau$ were simulated. Numerical results are summarized in Fig. 14 in terms of peak-to-peak voltage $v_{p p}$ versus impulse duration $\tau$.

Every harvester generates the maximum voltage for a specific duration of the impulse. The value of the maximum voltage depends on the natural frequency of the first bending mode.

The harvesters with low frequency bending modes (configurations e and f) generate higher voltages than PPA1001 and reach the best performance with long impulses $(\tau \approx 12 \mathrm{~ms}$ ). The harvesters with high frequency bending modes (configurations $\mathrm{c}$ and d), in agreement with analytical results, generate less voltage than PPA1001 and reach the best performance for short impulses $(\tau \approx 3 \mathrm{~ms}$ ). It is worth highlighting that in the presence of short duration impulses, the best design choice sometimes consists in lowering the natural frequency of the harvester inasmuch as numerical simulations (Fig. 14) and analytical calculations (Fig. 5) show that the increase in the response of the harvester compensates for the non-optimal tuning of the harvester to the impulse.

Table 3

Results of numerical modal analysis.

\begin{tabular}{|c|c|c|c|c|c|c|}
\hline Harvester & $\mathrm{L}[\mathrm{mm}]$ & $b_{c}[\mathrm{~mm}]$ & $b_{e}[\mathrm{~mm}]$ & $\begin{array}{l}\text { 1st natural frequency } \\
{[\mathrm{Hz}] \text { and modal shape }}\end{array}$ & $\begin{array}{l}\text { 2nd natural frequency } \\
\text { [Hz] and modal shape }\end{array}$ & $\begin{array}{l}\text { 3rd natural frequency } \\
{[\mathrm{Hz}] \text { and modal shape }}\end{array}$ \\
\hline a. PPA 1001 & 41.1 & 20.8 & 20.8 & $\begin{array}{l}122 \\
\text { bending }\end{array}$ & $\begin{array}{l}503 \\
\text { torsion }\end{array}$ & $\begin{array}{l}760 \\
\text { bending }\end{array}$ \\
\hline b. PPA 1001 with tip mass & 41.1 & 20.8 & 20.8 & $\begin{array}{l}55 \\
\text { bending }\end{array}$ & $\begin{array}{l}267 \\
\text { torsion }\end{array}$ & $\begin{array}{l}543 \\
\text { bending }\end{array}$ \\
\hline c. Wide rectangular & 27.4 & 31.2 & 31.2 & $\begin{array}{l}276 \\
\text { bending }\end{array}$ & $\begin{array}{l}598 \\
\text { torsion }\end{array}$ & $\begin{array}{l}1577 \\
\text { plate mode }\end{array}$ \\
\hline d. Tapered & 32.9 & 31.2 & 20.8 & $\begin{array}{l}212 \\
\text { bending }\end{array}$ & $\begin{array}{l}667 \\
\text { torsion }\end{array}$ & $\begin{array}{l}1208 \\
\text { bending }\end{array}$ \\
\hline e. Inverse tapered & 54.8 & 10.4 & 20.8 & $\begin{array}{l}56 \\
\text { bending }\end{array}$ & $\begin{array}{l}342 \\
\text { torsion }\end{array}$ & $\begin{array}{l}396 \\
\text { bending }\end{array}$ \\
\hline f. Triangular & 82.2 & 20.8 & 0 & $\begin{array}{l}61 \\
\text { bending }\end{array}$ & $\begin{array}{l}271 \\
\text { bending }\end{array}$ & $\begin{array}{l}675 \\
\text { bending }\end{array}$ \\
\hline
\end{tabular}

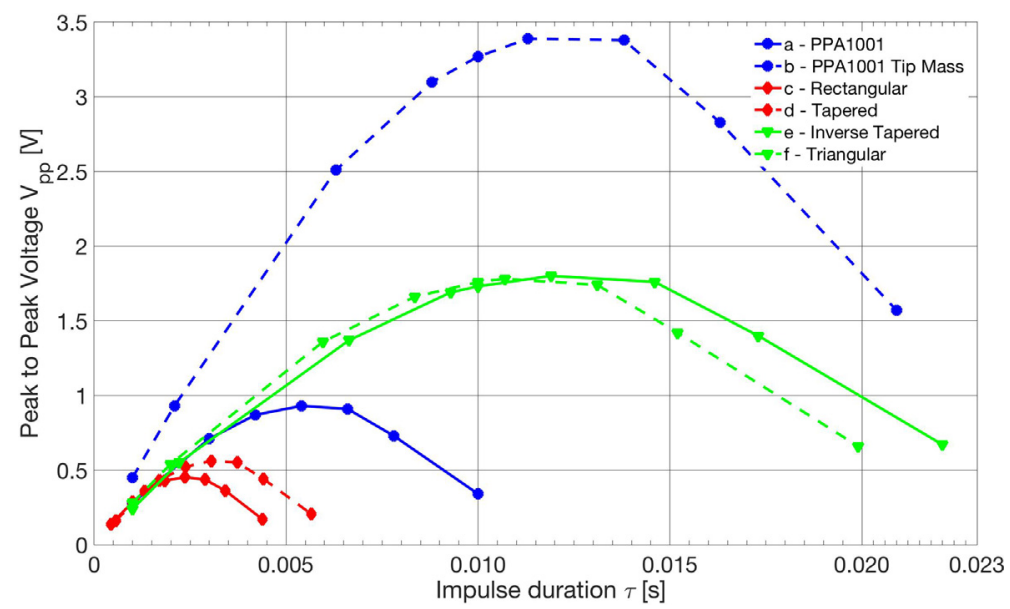

Fig. 14. Peak-to-peak voltage of different harvesters against impulse duration (half-sine impulse with maximum acceleration $1 \mathrm{~g}$ ). 
The harvester with tip mass generates a very large voltage because the added mass not only lowers the natural frequency, but also increases the modal forcing function $\left(F_{r}\right)$; this effect is thoroughly described in [6]. The main drawback of this solution may be the increase in the stress inside the PZT layer.

For comparison purposes it is useful to represent numerical results in terms of non-dimensional quantities. The first quantity is the normalized impulse duration $\tau_{\text {norm }}$ (in which the natural period $T_{r}$ is the one of the first bending mode). The output of the harvester is represented by the normalized peak-to-peak voltage:

$$
v_{\text {norm }}=\frac{v_{p p} / 2}{a_{c}\left|H\left(\omega_{r}\right)\right|}
$$

which is the ratio between $v_{p p} / 2$ and the voltage generated by the harvester when it is excited at its resonance condition by an harmonic input having the same amplitude $\left(a_{c}\right) . v_{\text {norm }}$ can also be defined as the ratio between the voltage generated in transient condition and the voltage that the harvester can generate in the best steady state condition.

Fig. 15 shows that the various harvesters reach the best performance when $\tau_{\text {norm }}=0.675$, in agreement with analytical results. In the best tuning condition, all the harvester generate the same $v_{\text {norm}}$, which corresponds to a small fraction of the voltage generated at resonance by an harmonic input having the same amplitude $\left(a_{c}\right)$.

\subsection{Impulses caused by human gait}

The response of the harvesters to a more complex impulse was considered. In particular, owing to the practical interest, the response of the harvesters to the acceleration impulse caused by heel strike in human gait was simulated. Various authors $[18,19]$ highlighted that this acceleration impulse is mainly directed in the vertical direction and can be represented by a large positive peak (pointing up from the ground) followed by a minor negative peak (Fig. 16). The amplitude and dura-

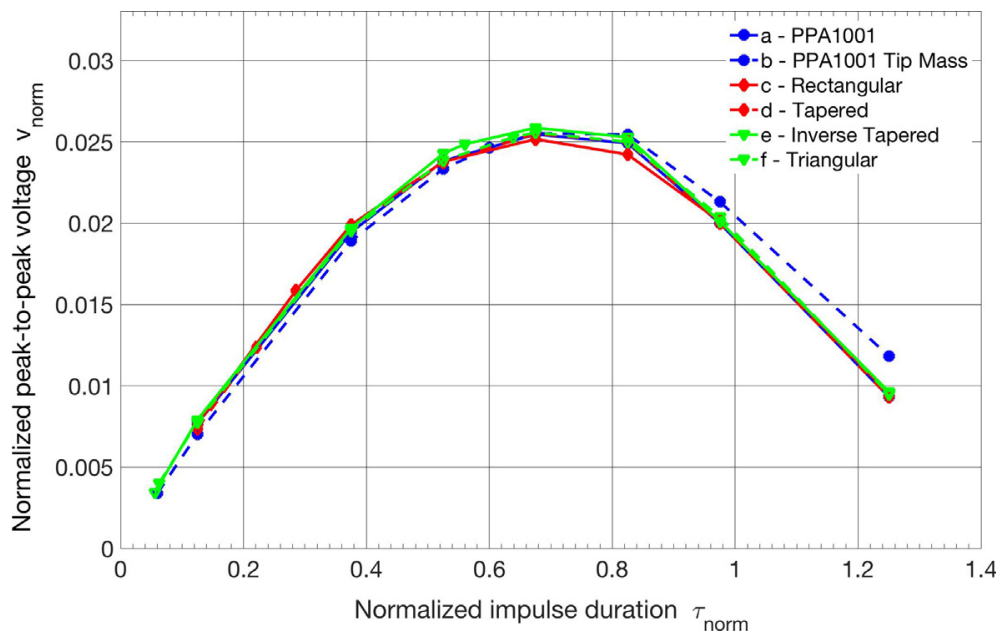

Fig. 15. Normalized peak-to-peak voltage of different harvesters against normalized impulse duration (half-sine impulse with maximum acceleration $1 \mathrm{~g}$ ).

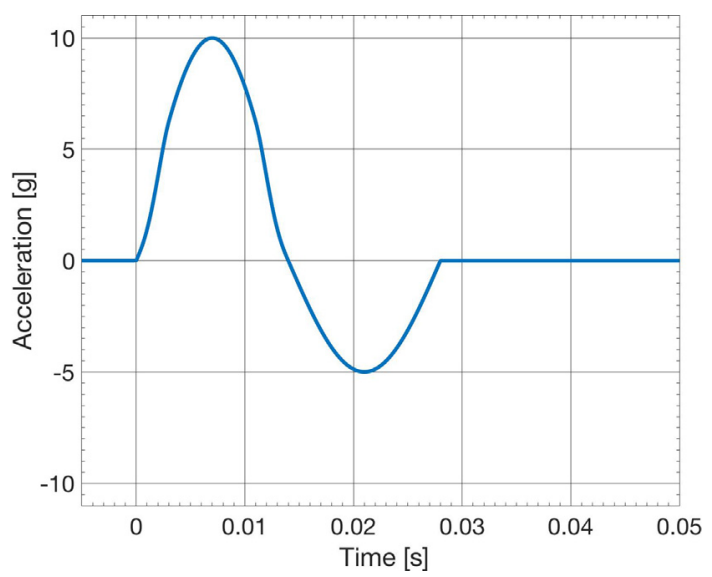

Fig. 16. Schematization of impulse acceleration due to heel strike in human gait. 


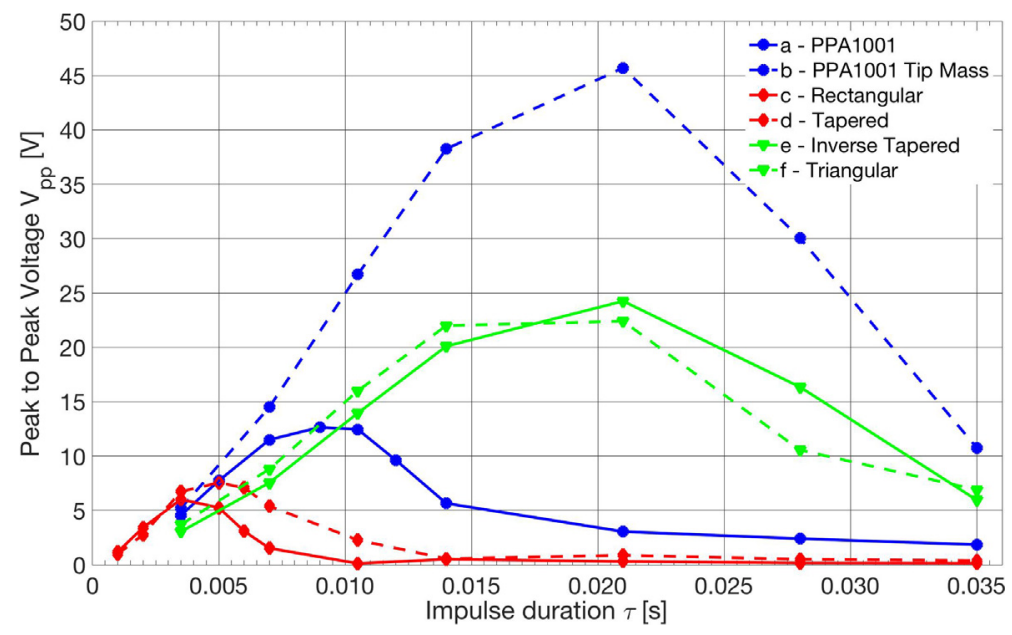

Fig. 17. Peak-to-peak voltage of different harvesters against impulse duration (human gait impulse).

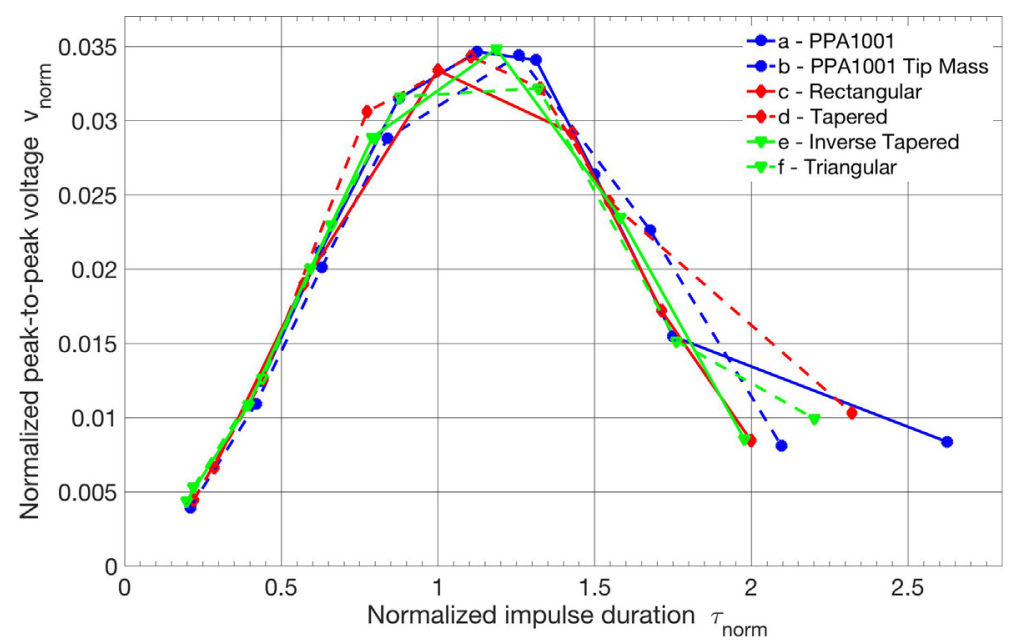

Fig. 18. Normalized peak-to-peak voltage of different harvesters against normalized impulse duration (human gait impulse).

tion of these acceleration peaks depend on the walking/running patterns, on the subject and on the characteristics of shoes. The major peak ranges from 5 to $30 \mathrm{~g}$, the minor peak is about half the major peak $[18,19]$. The sequence of two peaks occurs in some tens of $\mathrm{ms}$ [19]. In this research the two peaks were represented by two half-sine impulses joined for $\tau / 2$ by a smooth function. The amplitudes of the peaks were kept constant $(+10 \mathrm{~g}$ and $-5 \mathrm{~g}$ respectively) and the duration was varied between 4 and $35 \mathrm{~ms}$.

Fig. 17 deals with the simulated response of the harvesters loaded by impulses caused by human gait. Harvester PPA 1001 achieves the best performance when impulse duration $\tau$ is about $9 \mathrm{~ms}$. This value is rather small and, in order to tune the harvesters to the typical duration of the peak-valley sequence shown in Fig. 16, the natural frequency of the first bending mode has to be lowered. This result can be achieved by adding a tip mass (harvester b) or by adopting the inverse tapered or triangular geometries (harvesters e and f). These solutions also lead to an increase in the FRF amplitude that has a ben-eficial effect on the generated voltage. Harvesters tuned to high frequencies (harvesters c and d) are not suited to exploit impulses caused by human gait.

Also in this case results can be presented in non-dimensional way. Fig. 18 shows that the maximum performance of the harvester is achieved when the impulse duration is about $120 \%$ the natural period of the first bending mode $\left(\tau_{\text {norm }}=1.2\right)$. This numerical result roughly agrees with analytical results since $\tau_{\text {norm }}=1.2$ corresponds to a main half-sine peak having duration equal to $0.60 T_{r}$.

\section{Concluding remarks}

This paper deals with the problem of efficiently exploiting acceleration impulses by means of piezoelectric harvesters. An analytical study based on ideal impulses and a single mode representation of the harvester has given design guidelines that 
have proved to hold true also in the presence of actual impulses and more complex harvesters (tapered, inverse tapered and triangular geometry).

A detailed 3D numerical model of a unimorph cantilever has been developed and experimentally validated and the parametric structure of the model makes it possible to simulate harvesters with different geometries.

Numerical simulations have shown that the impulsive response of both rectangular and trapezoidal harvesters depends on the first bending mode, while higher order modes can be safely neglected.

Numerical simulations and experimental results have shown that a harvester with a certain natural frequency can efficiently harvest mechanical energy only if excited by an impulse whose duration has a specific relation with the natural period of oscillation of the first bending mode of the harvester itself. The maximum peak-to-peak voltage generated in transient condition is always a small fraction of the voltage that the harvester can generate in steady-state condition, when excited in resonance by an harmonic input with the same amplitude.

The problem of modifying the natural frequency to tune the harvester to the impulse has been considered as well. Numerical simulations have shown that, when the natural frequency has to be lowered, there are various solutions which may differ for the level of stress generated inside the piezoelectric material.

Further studies will deal with the response to repeated impulses and the borderline between impulsive and periodic excitation.

\section{Acknowledgments}

The research was carried out in the framework of the research program: "Piezoelectric Micro-Electro-Mechanical Power Supply for Automotive Wireless Sensors" funded by University of Padova - Italy grant CPDA142798.

\section{Appendix A}

See Tables A1-A3.

Table A1

Substrate materials properties.

\begin{tabular}{llll}
\hline Material & Elastic modulus E & Poisson's ratio $v$ & Density $\rho$ \\
\hline Polyester & $3.65 \mathrm{GPa}$ & 0.48 & $1380 \mathrm{~kg} / \mathrm{m}^{3}$ \\
Copper & $110 \mathrm{GPa}$ & 0.34 & $1300 \mathrm{~kg} / \mathrm{m}^{3}$ \\
Steel AISI 304 & $193 \mathrm{GPa}$ & 0.29 & $8000 \mathrm{~kg} / \mathrm{m}^{3}$ \\
Polyimide & $4.1 \mathrm{GPa}$ & 0.34 & $1410 \mathrm{~kg} / \mathrm{m}^{3}$
\end{tabular}

Table A2

PZT 5H properties'.

\begin{tabular}{llll}
\hline Property & Symbol & Value & Unit \\
\hline Relative permittivity & $\varepsilon_{33}^{\mathrm{T}}$ & 3800 & \\
Piezoelectric constant & $\mathrm{d}_{31}$ & $-320 \cdot 10^{-12}$ & $\mathrm{C} / \mathrm{N}$ \\
Piezoelectric constant & $\mathrm{d}_{33}$ & $650 \cdot 10^{-12}$ & $\mathrm{C} / \mathrm{N}$ \\
Young's modulus & $\mathrm{Y}_{11}^{\mathrm{E}}$ & $6.3 \cdot 10^{10}$ & $\mathrm{~Pa}$ \\
Young's modulus & $\mathrm{Y}_{33}^{\mathrm{E}}$ & $5.0 \cdot 10^{10}$ & $\mathrm{~Pa}$ \\
Density & $\rho$ & 7800 & $\mathrm{~kg} / \mathrm{m}^{3}$ \\
\hline
\end{tabular}

Table A3

Dimensional properties of the harvester.

\begin{tabular}{lll}
\hline Geometric cantilever properties & Symbol & Value [mm] \\
\hline Cantilever length & $\mathrm{L}$ & 42.9 \\
Cantilever width & $\mathrm{b}$ & 23.3 \\
Cantilever thickness & $\mathrm{h}$ & 0.41 \\
PZT 5H thickness & $\mathrm{hPZT}$ & 0.15 \\
Steel thickness & $\mathrm{hSt}$ & 0.15 \\
Copper thickness & $\mathrm{hCu}$ & 0.03 \\
Polyimide thickness & $\mathrm{hPm}$ & 0.03 \\
Polyester thickness & $\mathrm{hPs}$ & 0.05 \\
Lateral edge & $\mathrm{Le}$ & 1.25 \\
Tip edge & $\mathrm{Te}$ & 1.80 \\
\hline
\end{tabular}




\section{References}

[1] K.B. Singh, V. Bedekar, S. Taheri, S. Priya, Piezoelectric vibration energy harvesting system with an adaptive frequency tuning mechanism for intelligent tires, Mechatronics 22 (2012) 970-988.

[2] S.R. Anton, H.A. Sodano, A review of power harvesting using piezoelectric materials (2003-2006), Smart Mater. Struct. 16 (2007) R1-R21.

[3] M.A. Hannan, S. Mutashar, S.A. Samad, A. Hussain, Energy harvesting for the implantable biomedical devices: issues and challenges, BioMed. Eng. OnLine 13 (79) (2014).

[4] N.S. Shenck, J.A. Paradiso, Energy scavenging with shoe-mounted piezoelectrics, IEEE MICRO 22 (3) (2001) $30-42$.

[5] T.J. Kazmierski, S. Beeby, Energy Harvesting Systems: Principles, Modeling and Applications, Springer, New York, USA, 2011.

[6] S. Priya, D.J. Inman, Energy Harvesting Technologies, Springer, New York, USA, 2009.

[7] S. Sadeqi, S. Arzanpour, K.H. Hajikolaei, Broadening the frequency bandwidth of a tire-embedded piezoelectric-based energy harvesting system using coupled linear resonating structure, IEEE/ASME Trans. Mechatron. 20 (5) (2015) 2085-2094.

[8] Z. Zhou, W. Qin, P. Zhu, A broadband quad-stable energy harvester and its advantages over bi-stable harvester: simulation and experiment verification, Mech. Syst. Signal Process. 84 (2017) 158-168.

[9] S. Adhikari, I.M. Friswell, D.J. Inman, Piezoelectric energy harvesting from broadband random vibrations, Smart Mater. Struct. 18 (11) (2009).

[10] P. Pillatsch, E.M. Yeatman, A.S. Holmes, A scalable piezoelectric impulse-excited energy harvester for human body excitation, Smart Mater. Struct. 21 (11) (2012).

[11] M.A. Ilyas, J. Swingler, Piezoelectric energy harvesting from raindrop impacts, Energy 90 (2015) $796-806$.

[12] K.H. Mak, S. McWilliam, A.A. Popov, Piezoelectric energy harvesting for tyre pressure measurement applications, Proc. IMechE Part D: J. Automobile Eng. 227 (6) (2013) 842-852.

[13] L. Gu, Low-frequency piezoelectric energy harvesting prototype suitable for the MEMS implementation, Microelectron. J. 42 (2011) $277-282$.

[14] M. Renaud, P. Fiorini, C. van Hoof, Low-frequency piezoelectric energy harvesting prototype suitable for the MEMS implementation, Smart Mater. Struct. 16 (2007) 1125-1135.

[15] S. Wei, H. Hu, S. He, Modeling and experimental investigation of an impact-driven piezoelectric energy harvester from human motion, Smart Mater. Struct. 22 (2013) 105020

[16] A.J. Lee, Y. Wang, D.J. Inman, Power harvesting prediction of piezoelectric stack actuator from a shock event, in: Proceedings of the ASME 2013 International Design Engineering Technical Conferences and Computers and Information in Engineering Conference IDETC/CIE, August 4-7, 2013.

[17] A. Doria, F. Moro, D. Desideri, A. Maschio, Z. Zhang, An impulsive method for the analysis of piezoelectric energy harvesters for intelligent tires, in: Proceedings of the ASME 2016 International Design Engineering Technical Conference and Computers and Information in Engineering Conference, IDETC/CIE August 21-24, 2016, Charlotte, United States, vol. 3, 2016, pp. V003T01A025.

[18] K. Ylli, D. Hoffmann, A. Willmann, P. Becker, B. Folkmer, Y. Manoli, Energy harvesting from human motion: exploiting swing and shock excitations, Smart Mater. Struct. 24 (2) (2015).

[19] L. Moro, D. Benasciutti, Harvested power and sensitivity analysis of vibrating shoe-mounted piezoelectric cantilevers, Smart Mater. Struct. 19 (11) (2010).

[20] E. Jacquelin, S. Adhikari, M.I. Friswell, A piezoelectric device for impact energy harvesting, Smart Mater. Struct. 20 (2011) 105008

[21] M. Pozzi, Impulse excitation of piezoelectric bimorphs for energy harvesting: a dimensionless model, Smart Mater. Struct. 23 (2014) 045044.

[22] D.J. Inman, Engineering Vibration, fourth ed., Pearson, 2013.

[23] J. Dicken, P.D. Mitcheson, I. Soianov, E.M. Yeatman, Power-extraction circuits for piezoelectric energy harvesters in miniature and low-power applications, IEEE Trans. Power Electron. 27 (11) (2012) 4514-4529.

[24] S. Roundy, P.K. Wright, A piezoelectric vibration based generator for wireless electronics, Smart Mater. Struct. 13 (5) (2004) 1131-1142

[25] N.M.M. Maia, J.M. Montalvao e Silva, Theoretical and Experimental Modal Analysis, John Wiley \& Sons Inc, New York, 1997.

[26] C.W. de Silva, Vibration: Fundamentals and Practice, second ed., CRC Press, 2006.

[27] COMSOL Multiphysics. <https://www.comsol.com>.

[28] M. Rosa, C.J. De Marqui, Modeling and analysis of a piezoelectric energy harvester with varying cross-sectional area, Shock Vib. 2014 (2014).

[29] S.P. Matova, M. Renaud, M. Jambunathan, M. Goedbloed, R. Van Schaijk, Effect of length/width ratio of tapered beams on the performance of piezoelectric energy harvesters, Smart Mater. Struct. 22 (7) (2013).

[30] D. Benasciutti, L. Moro, S. Zelenika, E. Brusa, Vibration energy scavenging via piezoelectric bimorphs of optimized shapes, Microsyst. Technol. 16 (2010) 657-668.

[31] K.M. Tsuruta, D.A. Rade, R.M. Finzi Neto, A.A. Cavalini Jr., Experimental evaluation of a cruciform piezoelectric energy harvester, Mech. Syst. Signal Process. 17 (2016) 141-148.

[32] A. Erturk, D.J. Inman, On mechanical modeling of cantilevered piezoelectric vibration energy harvesting, J. Intell. Mater. Syst. Struct. 19 (2008). 